
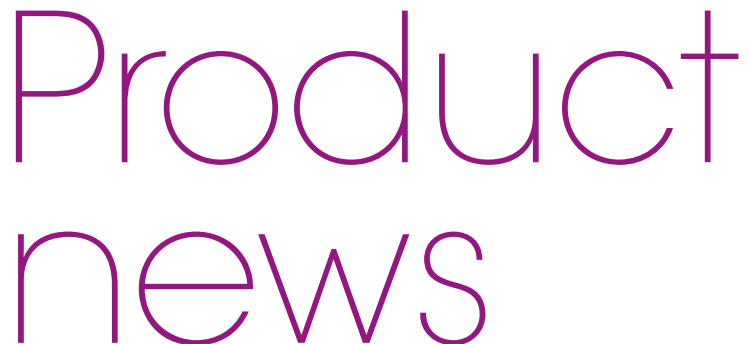

Product news is provided as a service to readers using text and images from the manufacturer, supplier or distributor and does not imply endorsement by BDJ Team. Normal and prudent research should be exercised before purchase or use of any product mentioned.

\section{ELEVATE YOUR PRACTICE}

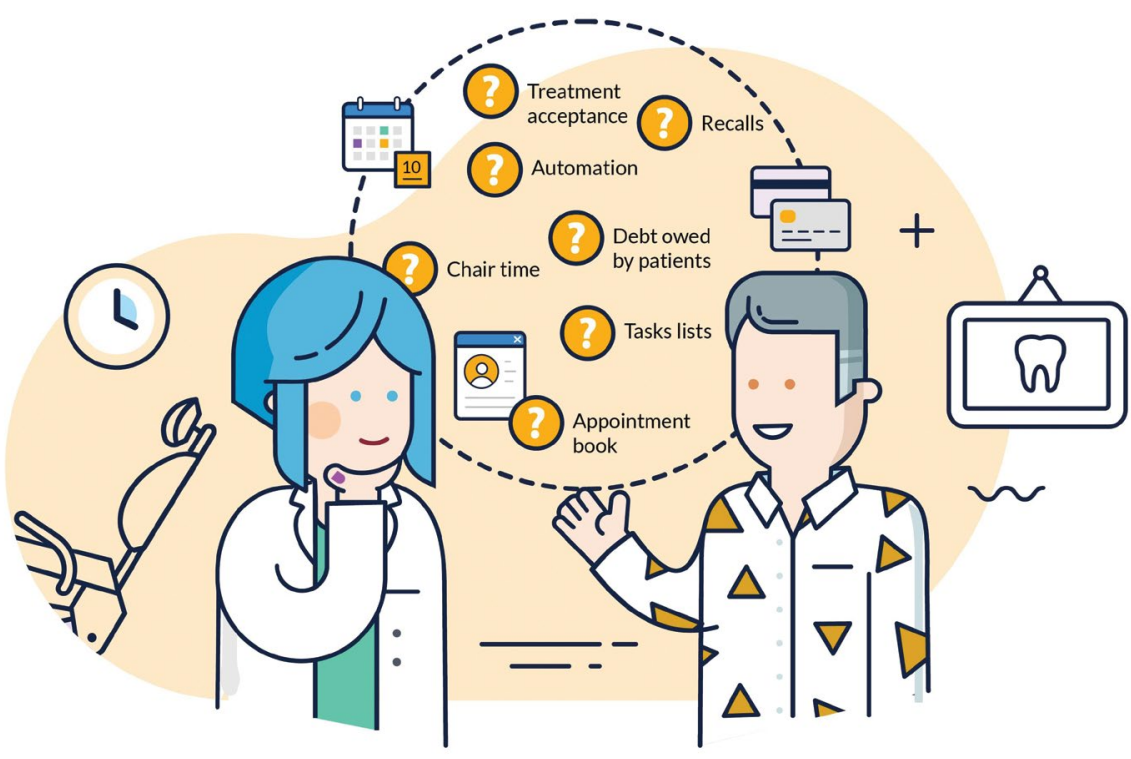

Dentally has launched Elevate - a new way to support you and your practice at every step of your journey, and as part of its commitment to leveraging the power of cloud-enabled practice management software in your dental practice.

The Elevate programme provides your practice with a consultant $100 \%$ dedicated to seeking to understand your practice priorities and aspirations. Your adviser will tailor the support they provide to your individual needs supporting you and helping you understand your business opportunities and optimise your workflow efficiencies - backed by benchmarked data and delivering you tangible outcomes like so many other practices across the UK.

After the tumultuous few years dental practices across the UK have had to deal with as a result of COVID-19, now more than ever, Dentally's team are there for you to help you find your feet once more and get your practice back up and running in the most efficient and effective of ways. The Elevate programme can help you to do exactly that. Ninety-two percent of Dentally's customers said that the programme had a significant or major impact on their business outcomes in 2021.

For no added cost, just a little bit of dedicated time set aside to talk support and how they can help, the Elevate programme is available to all Dentally customers to help streamline their practices. To book an initial call with your own Elevate consultant, visit the following link and book a convenient time for you online: https:// www.dentally.co/uk/about-dentally/elevate. Elevate your practice now and leverage the power of the cloud.

For more information visit: https:// dentally.co/ or call 02038565610.
PROTECT GUMS AND THE PLANET WITH \section{$100 \%$ RECYCLABLE TOOTHPASTE}

Boasting a $100 \%$ recyclable carton, tube and cap, vegan friendly formula, and clinically proven to improve gum health, the Arm \& Hammer 100\% Natural Gum Protection Toothpaste is perfect for patients wanting to do good and feel good.

In the brand-new $100 \%$ natural toothpaste range from Arm and Hammer, the $100 \%$ Natural Gum Protection Toothpaste is powered by baking soda gently removing plaque and stains to leave patients with a whiter, brighter smile and long-lasting oral health.

Its benefits include:

- Remineralises tooth enamel

- Neutralises acids caused by everyday food and drink

- Returns oral $\mathrm{pH}$ to neutral levels

- Provides lasting freshness

- $100 \%$ recyclable (carton, tube and cap)

- No preservatives

- No artificial colours

- Vegan friendly

- Quickly dissolves to clean the total tooth surface fast

- Deep cleans by getting between teeth and right up to the gum line

- Clinically-proven.

For more information about the carefully formulated Arm \& Hammer toothpaste range, visit https://www. armandhammer.co.uk/ or email: ukenquiries@churchdwight.com.

Arm \& Hammer 100\% Natural Baking Soda Toothpaste range can now be purchased from Boots, Amazon and Superdrug, with further stockists following.

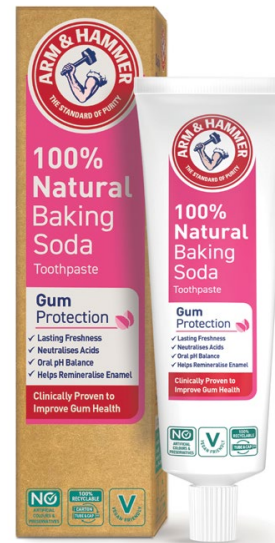

